\title{
Analysis of the Morphological Diversity of Inflorescence of Six Tunisian Date Palm (Phoenix dactylifera L.) Pollinators
}

\author{
K. Kadri, K. Aounallah, and M. Abdelhafidh
}

\section{ABSTRACT}

Six Tunisian date palm pollinators were morphologically characterized at the inflorescence level. The aim was to assess the level of similarity between the spathe of the three flowering stages. Nineteen qualitative and quantitative characteristics were explored and subjected to multivariate analyzes. The results showed that inflorescences morphological similarity oscillated between 97.9 and $62.2 \%$ with an average of $80.1 \%$, which testifies strong genetic relations among the six genotypes and among flowering stages/cycles within each genotype. Principal Component Analysis (PCA) analysis shows that weight of the spathe (SW), number of spathe (NS), shape of spathe (SS), total length of the spathe (TLS), shape of spikelets (SPS), number of spikelets per spathe (NS), These characteristics are defined by axis 1 and 2 which absorbing a total of $56.3 \%$ of total variability. Phylogenetic relationship analysis showed that two groups were distinguished by a high level of genetic similarity of inflorescences at each flowering stage. According to the analysis, the second flowering stage is the most distinguished morphologically with the highest sizes of the quantitative characteristics studied.

Keywords: Date palm, Dendrogram, Flowering, Inflorescences, Quantitative and qualitative traits, Pollinator, PCA.

\section{INTRODUCTION}

The cultivation of the date palm (Phoenix dactylifera L.) occupies an important place in the agricultural production system in Tunisia and ranks second in terms of exports of agricultural products after olive oil [1]. This crop representing a major source of income for farmers and related industries in several oasis located in the South West of Tunisia [2]. As a dioecious specimen, date palm is at the origin of an exceptional varietal richness [3] where each seed sown can indeed constitute a new variety that makes counting the existing varieties a more difficult process [4]. The Tunisian phoenicultural heritage is characterized by a great varietal diversity represented by more than 300 varieties [5]. The traditional oasis ecosystem constitutes a reservoir for the genetic diversity of the date palm crop which is now threatened with disappearance for various causes (silting up, lack of water, aging, monovarietal phoenici culture, etc.). Since antiquity, the selection and the distinction only affect
Submitted : July 30, 2021

Published : August 20, 2021

ISSN: $2684-1827$

DOI: 10.24018 /ejfood.2021.3.4.346

\section{K. Kadri*}

Regional Research Center on Oasis Agriculture, Tozeur road km1, BO 62, 2260 Degache, Tunisia.

National Institute of Agronomic Research of Tunis, Laboratory of Biotechnology applied on Agriculture, Hedi Karray street, 2049, Ariana, University of Carthage, Tunisia.

(e-mail: Kadri.karim@ ${ }^{\circledR}$ iresa.agrinet.tn) K. Aounallah

National Institute of Agricultural Sciences of Tunis, 43, Charles NICOLE Street 1082, City of Mahrajen, Tunis, Tunisia.

(e-mail: aounallahkarim@yahoo.fr) M. Abdelhafidh

National Institute of Agricultural Sciences of Tunis, 43, Charles NICOLE Street 1082, City of Mahrajen, Tunis, Tunisia. (e-mail:

benabdelhafidhmanar96@gmail.com)

*Corresponding Author the female date palm, in Tunisia; it was rarely question of selection and characterization of the male date palm, locally named "Dokkars". In this context, a certain number of works have been carried out on the characterization and evaluation of some populations of dokkars, we cite: the work of Karim et al. [6]; Kadri et al. [7]; Kadri et al. [8]; Elkadri et al. [9]. In Tunisia, the flowering of male spathe begins from the end of February until April for most cultivars [10]. Generally, date palm male trees produce their spathes (inflorescences) in cycles/waves during the flowering period that mostly extend to more than a month. However, there is little available information on spathe morphology for each flowering stage. Our work aims to identify the "Dokkars" by morphological characterization of the inflorescences and to assess the genetic diversity existing between the three flowering stages. 


\section{MATERIALS AND METHODS}

\section{A. Plant Materials}

Six date palm pollinators were chosen for this study, these cultivars belong to the experimental plot of the regional agricultural research center of Degache (E: 33 ${ }^{\circ} 58^{\prime} 40.5^{\prime \prime}$; N: $\left.008^{\circ} 12^{\prime} 31.8^{\prime \prime}\right)$. The pollinators have the same age category and undergo the same cultivation technique (fertilization and irrigation ...). Each male foot is presented by a code: ABD1, P4, P13, P3, P7 and P8 (Fig. 1).
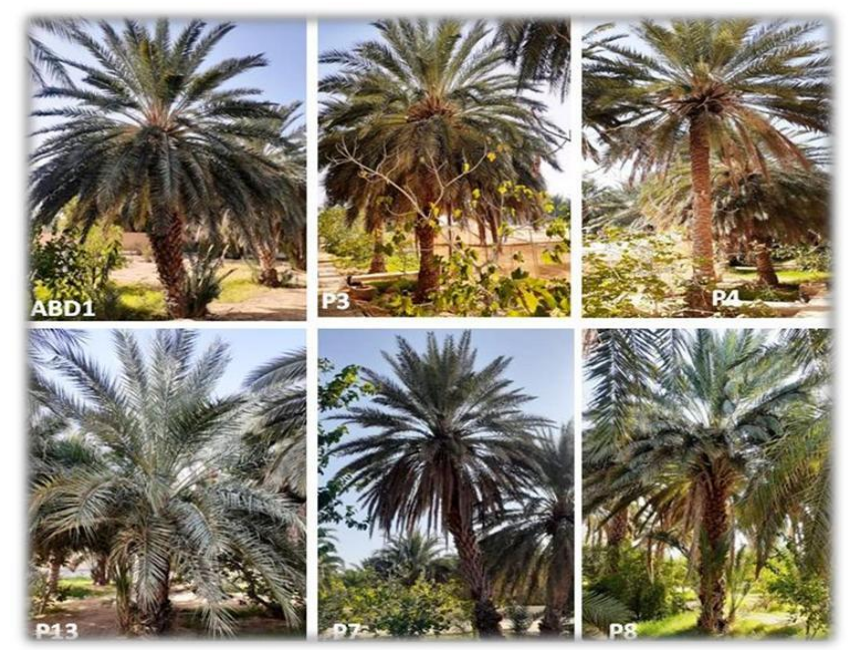

Fig. 1. On-site image of the selected six male date palm genotypes used in the current study.

\section{B. Morphological Characterization of Inflorescence}

The morphological characterization of the inflorescences of the six male date palm genotypes (Fig. 2) at each flowering stages/cycles (early, medium, and late) during the flowering period were performed according to the parameters listed in the descriptor of the date palm of IPGRI [11] (Table I), using inflorescences at each flowering cycle for each genotype. These phenotypic characteristics of the inflorescences were used to establish a descriptive sheet of the various male genotypes. the collection of male spathes was done just one day after flowering, for each stage three inflorescences are collected to carry out the measurements.
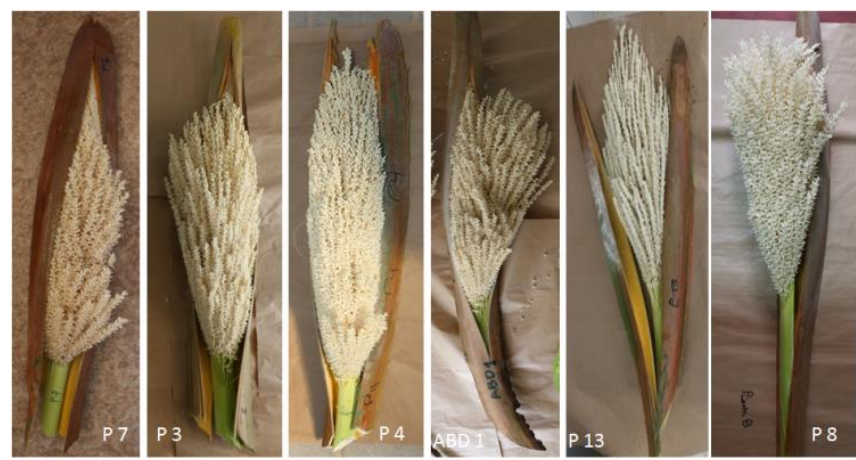

Fig. 2. Spathe image of the six male date palm genotypes used in this study.

\section{Statistical Analysis}

For the analysis of the morphological diversity of the inflorescences of six pollinators, three repetitions were performed for each flowering stage (early, medium, and late). Principal Component Analysis (PCA) in this study was performed using Multi-Variate Statistical Package software (MVSP 3.22). The coefficient of similarity was used by the NTSYS software to establish the dendrogram corresponding to the grouping of the different six pollinators according to the WPGMA "Weighted Pair-Group Method using Arithmetic" analysis [12].

TABLE I: LIST OF THE USED PARAMETERS FOR MALE INFLORESCENCE CHARACTERIZATION ACCORDING TO THE DESCRIPTOR OF THE DATE PALM

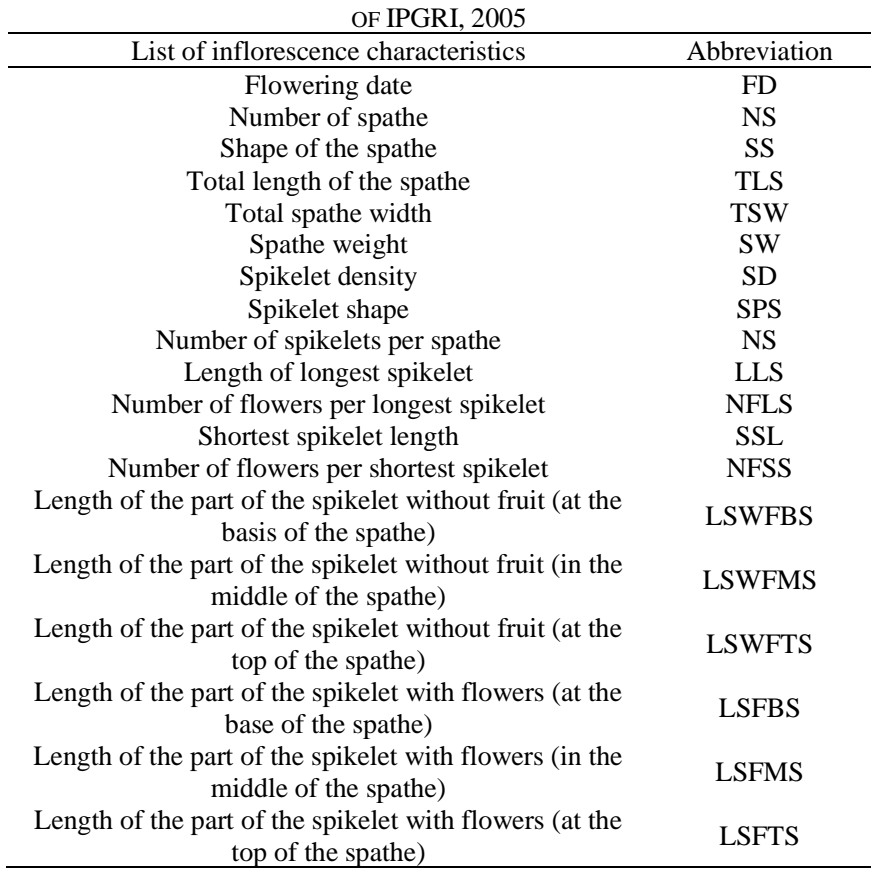

\section{RESULTS AND DISCUSSIONS}

\section{A. Principal Component Analysis}

Morphological parameters of the male inflorescences (Table II and III) were processed by principal component analysis (PCA) using MVSP software (3022) (Fig.3). Axis 1 (F1) and axis 2 (F2) were chosen, which absorbs the maximum of variability existing among the six male date palm genotypes. The first axis represents $33.4 \%$ while the second represents $22.9 \%$ of variability which absorbing a total of $56.3 \%$ variability. Axis 1 is defined by the following parameters: the weight of the spathe (SW), the density of the spikelets (SD), the shape of the spikelets (SPS), the length of the shortest spikelet (SSL), number of flowers per shortest spikelet (NFSS), the length of the part of the spikelet without fruit at the top of the spathe (LSWFTS), the length of the part of the spikelet with flowers in the middle of the spathe (LSFMS) and the length of the part of the spikelet with flowers at the top of the spathe (LSFTS). We conclude that these parameters are the most discriminative according to the first axis. While, axis 2 is defined by number of spathe (SN), shape of spathe (SS), total length of the spathe (TLS), number of spikelets per spathe (NS), length of the part of the spikelet without fruit at the base of the spathe (LSWFBS), length of the part without fruit in the middle of the spathe (LSFMS) and length of the part of the spikelet with flower at the base of the spathe (LSFBS). The analysis of the PCA (Fig. 3) shows the existence of distinct groups.

Group A composed of the genotype 'P3' at all flowering stages which correlate negatively with axis 2 . In fact, the 
spathe of 'P3' passing from one stage to another and did not significantly stand out from each other and form an agglomeration by the characters which reflect this axis and were distinguished from other genotypes by the same criteria. Group B contained 'P7' genotype at all flowering stages and was positively correlated with axis 1 . However, the third group $\mathrm{C}$, included 'P4'genotype at the different flowering stages and was highly correlated with axis 2. Group D correlates positively with axis 2 and negatively with axis 1 and it consists of 'P13' from the various flowering stages.
Group E formed by the genotypes 'ABD1' S1 and 'P8' S1 and $\mathrm{S} 2$; and negatively correlated with axis 1 . These results show a morphological similarity between the genotypes 'ABD1' and 'P8' S1. The group F is made up of the genotypes 'ABD1' S3 and 'P8' S3 and correlate directly with axis 1 . These results show a similarity between the genotypes 'ABD1' and 'P8 S3'. The last group G is composed only of the genotype 'ABD1' S2and strongly correlated with axis 2 .

TABLE II: LIST OF QUANTITATIVE DESCRIPTORS OF THE INFLORESCENCE

\begin{tabular}{|c|c|c|c|c|c|c|c|c|}
\hline $\begin{array}{l}\text { Pollinators } \\
\text { Descriptors }\end{array}$ & ABD1 & $\mathrm{P} 4$ & $\mathrm{P} 7$ & P8 & P3 & $\mathrm{P} 13$ & $P$ value & LSD value \\
\hline & \multicolumn{8}{|c|}{ Inflorescences emitted during the first flowering stage } \\
\hline Flowering date & $28 / 02 / 20$ & $5 / 03 / 20$ & $4 / 03 / 20$ & $29 / 02 / 20$ & $19 / 03 / 20$ & $16 / 03 / 20$ & & \\
\hline NS & $11^{\mathrm{ab}}$ & $12^{\mathrm{a}}$ & $10^{\mathrm{b}}$ & $11^{\mathrm{ab}}$ & $8^{\mathrm{c}}$ & $12^{\mathrm{a}}$ & $<0.000$ & 2,9949337 \\
\hline TLS (cm) & $137^{\mathrm{b}}$ & $144^{\mathrm{a}}$ & $138^{\mathrm{b}}$ & $100^{\mathrm{e}}$ & $106^{\mathrm{d}}$ & $131^{\mathrm{c}}$ & $<0.000$ & 3,04534392 \\
\hline TSW (cm) & $13.5 \mathrm{e}$ & $15^{\mathrm{b}}$ & $18.5^{\mathrm{a}}$ & $18^{\mathrm{a}}$ & $14^{\mathrm{d}}$ & $14.5^{\mathrm{c}}$ & $<0.000$ & 0,95070275 \\
\hline SW (g) & $2250^{\mathrm{d}}$ & $3420^{\mathrm{a}}$ & $3325^{b}$ & $2385^{\mathrm{c}}$ & $2150^{\mathrm{e}}$ & $1873^{\mathrm{f}}$ & $<0.000$ & 19,2365547 \\
\hline NSS & $297,33^{\mathrm{d}}$ & $259,30^{\mathrm{e}}$ & $405,43^{\mathrm{a}}$ & $395,3^{\mathrm{b}}$ & $302,56^{\mathrm{c}}$ & $170,66^{\mathrm{f}}$ & $<0.000$ & 4,69829082 \\
\hline $\operatorname{LLS}(\mathrm{cm})$ & $41,49^{\mathrm{a}}$ & $34,49^{d}$ & $34,50^{\mathrm{d}}$ & $37,56^{\mathrm{b}}$ & $36,76^{\mathrm{c}}$ & $27,86^{\mathrm{e}}$ & $<0.000$ & 0,84154943 \\
\hline NFLS & $111^{\mathrm{a}}$ & $84^{\mathrm{d}}$ & $77^{\mathrm{e}}$ & $93^{c}$ & $95^{\mathrm{b}}$ & $72^{f}$ & $<0.000$ & 2,34914541 \\
\hline $\mathrm{SSL}(\mathrm{cm})$ & $7^{\mathrm{b}}$ & $4,03^{\mathrm{d}}$ & $8,5^{\mathrm{a}}$ & $8,33^{\mathrm{a}}$ & $3,69^{d}$ & $5,35^{\mathrm{c}}$ & $<0.000$ & 0,58597983 \\
\hline NFSS & $14^{\mathrm{c}}$ & $10^{\mathrm{d}}$ & $25^{\mathrm{a}}$ & $21^{\mathrm{b}}$ & $6^{\mathrm{e}}$ & $22^{\mathrm{b}}$ & $<0.000$ & 2,34914541 \\
\hline LSWFBS (cm) & $8^{a}$ & $3,66^{\mathrm{d}}$ & $7^{\mathrm{ab}}$ & $5,86^{\mathrm{bc}}$ & $5,33^{c}$ & $6,40^{\mathrm{bc}}$ & $<0.000$ & 1,45128269 \\
\hline LSWFMS (cm) & $4,43^{\mathrm{c}}$ & $3,90^{\mathrm{d}}$ & $6,30^{\mathrm{a}}$ & $4,90^{\mathrm{b}}$ & $3,03^{\mathrm{e}}$ & $2,96^{\mathrm{e}}$ & $<0.000$ & 0,3714325 \\
\hline LSWFTS $(\mathrm{cm})$ & $3^{\mathrm{a}}$ & $1,16^{\mathrm{d}}$ & $2,5^{\mathrm{b}}$ & $2,59^{\mathrm{b}}$ & $1^{\mathrm{d}}$ & $2^{c}$ & $<0.000$ & 0,25970779 \\
\hline LSFBS $(\mathrm{cm})$ & $13,89^{d}$ & $12,89^{\mathrm{e}}$ & $14,30^{\mathrm{c}}$ & $15,86^{\mathrm{b}}$ & $11,86^{\mathrm{f}}$ & $19,33^{\mathrm{a}}$ & $<0.000$ & 0,34578484 \\
\hline LSFMS (cm) & $16,03^{\mathrm{c}}$ & $23,03^{\mathrm{b}}$ & $14,69^{\mathrm{f}}$ & $15,03^{\mathrm{e}}$ & $25,03^{\mathrm{a}}$ & $15,36^{\mathrm{d}}$ & $<0.000$ & 0,34132292 \\
\hline \multirow[t]{2}{*}{ LSFTS $(\mathrm{cm})$} & $15,33^{\mathrm{a}}$ & $12,5^{\mathrm{c}}$ & $15,53^{\mathrm{a}}$ & $6,5^{\mathrm{e}}$ & $13,86^{\mathrm{b}}$ & $11,86^{\mathrm{d}}$ & $<0.000$ & 0,53683098 \\
\hline & \multicolumn{8}{|c|}{ Inflorescences emitted during the second flowering stage } \\
\hline Flowering date & $6 / 03 / 20$ & $14 / 03 / 20$ & $12 / 03 / 20$ & $5 / 03 / 20$ & $27 / 03 / 20$ & $23 / 03 / 20$ & & \\
\hline NS & $10^{\mathrm{c}}$ & $12^{\mathrm{ab}}$ & $14^{\mathrm{a}}$ & $9^{c}$ & $12^{\mathrm{ab}}$ & $14^{\mathrm{a}}$ & $<0.000$ & 4,532220 \\
\hline TLS (cm) & $116.5^{\mathrm{d}}$ & $152^{\mathrm{a}}$ & $145^{\mathrm{c}}$ & $105.5^{\mathrm{f}}$ & $112^{\mathrm{e}}$ & $147^{\mathrm{b}}$ & $<0.000$ & 2,5970779 \\
\hline TSW (cm) & $15^{\mathrm{e}}$ & $17^{\mathrm{d}}$ & $22^{\mathrm{b}}$ & $26^{\mathrm{a}}$ & $16^{\mathrm{de}}$ & $18.5^{\mathrm{c}}$ & $<0.000$ & 1,505205 \\
\hline SW (g) & $2300^{\mathrm{e}}$ & $3850^{\mathrm{a}}$ & $3598^{\mathrm{b}}$ & $2658^{c}$ & $2450^{\mathrm{d}}$ & $2453^{\mathrm{d}}$ & $<0.000$ & 28,89862 \\
\hline NSS & $306^{\mathrm{d}}$ & $290^{\mathrm{e}}$ & $427,60^{\mathrm{a}}$ & $405^{\mathrm{b}}$ & $352^{\mathrm{c}}$ & $205^{\mathrm{f}}$ & $<0.000$ & 5,9635195 \\
\hline $\operatorname{LLS}(\mathrm{cm})$ & $40,83^{\mathrm{a}}$ & $38,06^{\mathrm{b}}$ & $35,13^{\mathrm{c}}$ & $33,46^{\mathrm{d}}$ & $40,5^{\mathrm{a}}$ & $35,59^{\mathrm{c}}$ & $<0.000$ & 1,1032372 \\
\hline NFLS & $102^{\mathrm{b}}$ & $112^{\mathrm{a}}$ & $101^{\mathrm{b}}$ & $88^{c}$ & $112^{\mathrm{a}}$ & $87^{\mathrm{c}}$ & $<0.000$ & 2,34914541 \\
\hline $\mathrm{SSL}(\mathrm{cm})$ & $6,90^{\mathrm{c}}$ & $6,13^{\mathrm{d}}$ & $9,03^{\mathrm{a}}$ & $8^{\mathrm{b}}$ & $4,69^{\mathrm{e}}$ & $6,73^{c}$ & $<0.000$ & 0,42642004 \\
\hline NFSS & $18^{\mathrm{c}}$ & $15^{\mathrm{d}}$ & $40^{\mathrm{a}}$ & $19^{c}$ & $11^{\mathrm{e}}$ & $32^{\mathrm{b}}$ & $<0.000$ & 2,34914541 \\
\hline LSWFBS $(\mathrm{cm})$ & $6,96^{\mathrm{b}}$ & $4,46^{\mathrm{d}}$ & $10,76^{\mathrm{a}}$ & $6,5^{\mathrm{b}}$ & $7,06^{\mathrm{b}}$ & $5,66^{\mathrm{c}}$ & $<0.000$ & 0,6690369 \\
\hline LSWFMS (cm) & $4,43^{\mathrm{c}}$ & $5,01^{\mathrm{b}}$ & $9,30^{\mathrm{a}}$ & $4,46^{\mathrm{c}}$ & $5,03^{\mathrm{b}}$ & $4,5^{\mathrm{c}}$ & $<0.000$ & 0,43245265 \\
\hline LSWFTS $(\mathrm{cm})$ & $2,5^{\mathrm{a}}$ & $2^{\mathrm{b}}$ & $1,96^{\mathrm{b}}$ & $2,40^{\mathrm{a}}$ & $2,03^{\mathrm{b}}$ & $1,63^{\mathrm{c}}$ & $<0.000$ & 0,30327337 \\
\hline LSFBS $(\mathrm{cm})$ & $23,79^{\mathrm{c}}$ & $25,83^{\mathrm{a}}$ & $23^{\mathrm{d}}$ & $25,06^{\mathrm{b}}$ & $15,19^{\mathrm{e}}$ & $23,89^{\mathrm{c}}$ & $<0.000$ & 0,56466427 \\
\hline LSFMS (cm) & $27^{\mathrm{c}}$ & $37^{\mathrm{a}}$ & $21,23^{\mathrm{d}}$ & $16,66^{\mathrm{e}}$ & $17^{\mathrm{e}}$ & $30,63^{\mathrm{b}}$ & $<0.000$ & 0,64333998 \\
\hline \multirow[t]{2}{*}{ LSFTS $(\mathrm{cm})$} & $14,26^{\mathrm{c}}$ & $15,05^{\mathrm{b}}$ & $15^{\mathrm{b}}$ & $13,73^{\mathrm{d}}$ & $16,03^{\mathrm{a}}$ & $14,16^{\mathrm{c}}$ & $<0.000$ & 0,39152424 \\
\hline & \multicolumn{8}{|c|}{ Inflorescences emitted during the third flowering stage } \\
\hline Flowering date & $12 / 03 / 20$ & $24 / 03 / 20$ & $25 / 03 / 20$ & $13 / 03 / 20$ & $2 / 04 / 20$ & $31 / 03 / 20$ & & \\
\hline NS & $12^{\mathrm{a}}$ & $12^{\mathrm{a}}$ & $12^{\mathrm{a}}$ & $13^{\mathrm{a}}$ & $10^{\mathrm{b}}$ & $11^{\mathrm{ab}}$ & $<0.000$ & 3,08286495 \\
\hline TLS $(\mathrm{cm})$ & $85.5^{\mathrm{e}}$ & $135^{\mathrm{b}}$ & $136^{\mathrm{b}}$ & $89.5^{\mathrm{d}}$ & $92^{\mathrm{c}}$ & $142^{\mathrm{a}}$ & $<0.000$ & 2,59707799 \\
\hline TSW (cm) & $13.2^{\mathrm{c}}$ & $13^{\mathrm{cd}}$ & $17.5^{\mathrm{b}}$ & $19^{\mathrm{a}}$ & $10^{\mathrm{d}}$ & $13.3^{\mathrm{c}}$ & $<0.000$ & 1,33003032 \\
\hline SW (g) & $1481 \mathrm{f}$ & $3230^{\mathrm{a}}$ & $3156^{\mathrm{b}}$ & $2243^{c}$ & $1879^{\mathrm{e}}$ & $1902^{\mathrm{d}}$ & $<0.000$ & 14,0513023 \\
\hline NSS & $269,60^{d}$ & $243^{\mathrm{e}}$ & $392^{\mathrm{a}}$ & $317^{\mathrm{b}}$ & $277^{\mathrm{c}}$ & $163^{\mathrm{f}}$ & $<0.000$ & 6,75875626 \\
\hline $\operatorname{LLS}(\mathrm{cm})$ & $30,10^{\mathrm{d}}$ & $31,75^{\mathrm{bc}}$ & $32^{\mathrm{b}}$ & $31,23^{\mathrm{bc}}$ & $35,43^{\mathrm{a}}$ & $31^{\mathrm{c}}$ & $<0.000$ & 0,90093123 \\
\hline NFLS & $100^{\mathrm{a}}$ & $71^{\mathrm{b}}$ & $65^{\mathrm{c}}$ & $72^{\mathrm{b}}$ & $101^{\mathrm{a}}$ & $66^{c}$ & $<0.000$ & 2,59707799 \\
\hline $\mathrm{SSL}(\mathrm{cm})$ & $4,80^{\mathrm{c}}$ & $3,59^{\mathrm{e}}$ & $6,80^{\mathrm{a}}$ & $5,90^{\mathrm{b}}$ & $4,19^{d}$ & $5,69^{\mathrm{b}}$ & $<0.000$ & 0,40688393 \\
\hline NFSS & $10^{c}$ & $12^{\mathrm{c}}$ & $22^{\mathrm{b}}$ & $11^{\mathrm{c}}$ & $8^{\mathrm{d}}$ & $26^{\mathrm{a}}$ & $<0.000$ & 2,34914541 \\
\hline LSWFBS (cm) & $5,83^{\mathrm{b}}$ & $3^{\mathrm{d}}$ & $6^{\mathrm{b}}$ & $3,13^{\mathrm{d}}$ & $6,80^{\mathrm{a}}$ & $4,56^{\mathrm{c}}$ & $<0.000$ & 1,03735453 \\
\hline LSWFMS (cm) & $3,5^{\mathrm{c}}$ & $3,43^{\mathrm{c}}$ & $9,16^{\mathrm{a}}$ & $4,03^{\mathrm{b}}$ & $4,06^{\mathrm{b}}$ & $3,29^{\mathrm{c}}$ & $<0.000$ & 0,54533014 \\
\hline LSWFTS $(\mathrm{cm})$ & $0.9^{c}$ & $1,60^{\mathrm{b}}$ & $2,90^{\mathrm{a}}$ & $1,06^{\mathrm{c}}$ & $1^{\mathrm{c}}$ & $1,10^{\mathrm{c}}$ & $<0.000$ & 0,25970779 \\
\hline LSFBS $(\mathrm{cm})$ & $22,33^{\mathrm{a}}$ & $21,86^{\mathrm{b}}$ & $19^{c}$ & $17^{\mathrm{e}}$ & $7,23^{\mathrm{f}}$ & $18,03^{\mathrm{d}}$ & $<0.000$ & 0,43245265 \\
\hline LSFMS (cm) & $17,96^{\mathrm{c}}$ & $30,23^{\mathrm{a}}$ & $16,89^{\mathrm{d}}$ & $17,86^{\mathrm{c}}$ & $18,33^{\mathrm{c}}$ & $20,60^{\mathrm{b}}$ & $<0.000$ & 0,77517844 \\
\hline LSFTS $(\mathrm{cm})$ & $8,96^{\mathrm{e}}$ & $14^{\mathrm{a}}$ & $12,36^{\mathrm{b}}$ & $10,46^{\mathrm{d}}$ & $11,46^{\mathrm{c}}$ & $10,43^{\mathrm{d}}$ & $<0.000$ & 0,68264583 \\
\hline
\end{tabular}

$*$ NS :Number of spathe, TLS :Total length of the spathe, TSW: Total spathe width, SW: Spathe weight, NSS: Number of spikelets per spathe, LLS: Length of longest spikelet, NFLS: Number of flowers per longest spikelet, SSL: Shortest spikelet length, NFSS: Number of flowers per shortest spikelet, LSWFBS: Length of the part of the spikelet without fruit (at the basis of the spathe), LSWFMS : Length of the part of the spikelet without fruit (in the middle of the spathe), LSWFTS: Length of the part of the spikelet without fruit (at the top of the spathe), LSFBS :Length of the part of the spikelet with flowers (at the base of the spathe), LSFMS: Length of the part of the spikelet with flowers (in the middle of the spathe), LSFTS: Length of the part of the spikelet with flowers (at the top of the spathe). 
TABLE III: LIST OF QUALITATIVE DESCRIPTORS OF THE INFLORESCENCE

\begin{tabular}{|c|c|c|c|c|c|c|}
\hline $\begin{array}{l}\text { Pollinators } \\
\text { Descriptors }\end{array}$ & ABD1 & $\mathrm{P} 4$ & $\mathrm{P} 7$ & P8 & P3 & $\mathrm{P} 13$ \\
\hline \multicolumn{7}{|c|}{ Inflorescences emitted during the first flowering stage } \\
\hline Flowering date & $28 / 02 / 20$ & $5 / 03 / 20$ & $4 / 03 / 20$ & $29 / 02 / 20$ & $19 / 03 / 20$ & $16 / 03 / 20$ \\
\hline SS & Lanceolate & Lanceolate & Swollen & Lanceolate & Fusiform & Lanceolate \\
\hline SD & Cowardly & Densely & Medium & Medium & Medium & Cowardly \\
\hline SPS & Sinuous & Straight & Very sinuous & Very sinuous & Sinuous & Very sinuous \\
\hline \multicolumn{7}{|c|}{ Inflorescences emitted during the second flowering stage } \\
\hline Flowering date & $6 / 03 / 20$ & $14 / 03 / 20$ & $12 / 03 / 20$ & $5 / 03 / 20$ & $27 / 03 / 20$ & $23 / 03 / 20$ \\
\hline SS & Lanceolate & Lanceolate & Swollen & Lanceolate & Fusiform & Lanceolate \\
\hline SD & Medium & Densely & Medium & Medium & Medium & Cowardly \\
\hline SPS & Sinuous & Straight & Very sinuous & Sinuous & Sinuous & Very sinuous \\
\hline \multicolumn{7}{|c|}{ Inflorescences emitted during the third flowering stage } \\
\hline Flowering date & $12 / 03 / 20$ & $24 / 03 / 20$ & $25 / 03 / 20$ & $13 / 03 / 20$ & $2 / 04 / 20$ & $31 / 03 / 20$ \\
\hline SS & Lanceolate & Lanceolate & Swollen & Lanceolate & Fusiform & Lanceolate \\
\hline $\mathrm{SD}$ & Medium & Densely & Cowardly & Cowardly & Medium & Cowardly \\
\hline SPS & Very sinuous & Straight & Very sinuous & Sinuous & Sinuous & Very sinuous \\
\hline
\end{tabular}

*SS: Shape of the spathe, SD: Spikelet density, SPS: Spikelet shape.

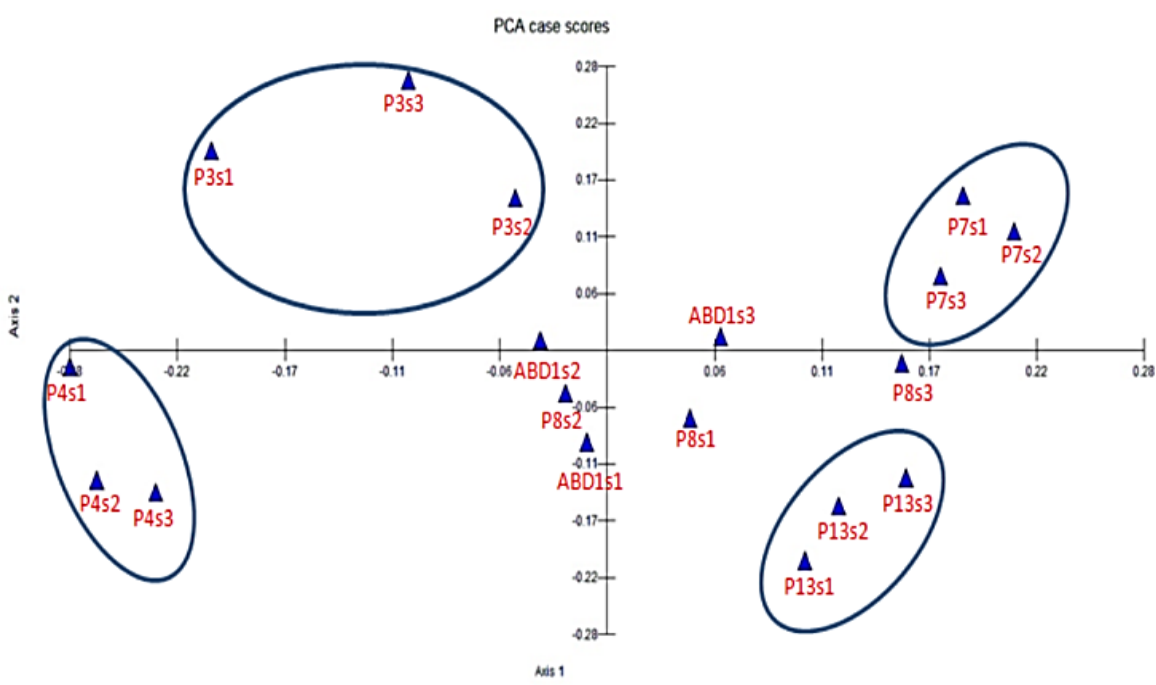

Fig. 3. Dispersion of the three flowering stages (S1, S2 and S3, referring to early, medium, and late floweringstage/cycle, respectively) for each of the six male date palm genotypes in a plane defined by F1 and F2 axes of the principal component analysis (PCA) based on the morphological characteristics of the inflorescences.

\section{B. Similarity Study}

The application of the software MVSP version (3.22) to all of the morphological of characteristics of inflorescences allowed us to obtain the matrix of the percentages of morphological similarities. Analysis of this matrix shows that the percentages of morphological similarity oscillate between 97.968 and $62.159 \%$ with an average of $80.062 \%$, which testified to a strong morphological similarity within each genotype for early, medium, and late flowering stage and among the studied genotypes. The studied genotypes constitute convergent groups, especially since the indices of the percentages of morphological similarity are mostly close to $100 \%$. The lowest coefficient $(62.15 \%)$ was observed between the combinations 'ABD1' S3 and 'P4' S2. These coefficients reflect a low similarity in the morphological characters of these two genotypes, reflecting a great genetic diversity. On the other hand, the highest coefficient (97.968\%) was recorded with the combinations of the genotypes 'AB1' S1and ABD1'S2 that resemble each other in a large number of characters, showing no morphological difference in spathe characteristics among the three flowering stages. According to Table II, the number of spathes developed per pollinator varies depending on flowering stage and cultivars. The total number of spathes varies from 30 to
36 , with an average of 11 spathe per pollinator per flowering stage. This number reminds the average number of palms developed by cultivar per year [13], [14] indicating that the spathe develops in the axils of palms. The work of Bchini [15] has shown that the number of spathes is little influenced by the year in almost all pollinators who have developed approximately the same number during the three years of measurement. Increases in the number of spathes can be influenced by irrigation disturbances [15]. Pollinator 13 was the one that recorded the maximum number of spathes developed (37), however, P3 was the one that gave the lowest number of spathe (30). The development of spathe can be late or early depending on the pollinator. Some pollinators begin to develop spathe in the autumn. The delay or precocity of the development of spathe in the same pollinator is influenced by the year [16]. In fact, the flowering of spathe constitutes one of the characteristics for the choice of pollinators. It owes its importance to the presence of pollen at the time of pollination. Before flowering, pollination of early date palms is only possible with pollen retained from the previous season, hence the need to select early flowering pollinators. In the sample tested, flowering of male spathe begins during the last week of February (ABD1) when certain varieties of date palm, mainly 'white dates' such as the variety 'Ammari' (the most early), are already receptive. According to Zaid and De Wet 
[17], flowering occurs when the temperature reaches over $18{ }^{\circ} \mathrm{C}$. Flowering continues until the first week of April (P3). From the results of Table 1, the maximum flowering rate is recorded during the month of March $\left(10^{\text {th }}\right.$ to $12^{\text {th }}$ calendar week). According to Table I, the analysis of variance shows a highly significant difference between pollinators in terms of spathe length and according to flowering stage. These results indicate that the length of the spathe is under the predominance of genetic control. The variations recorded according to flowering stage are significant. From the results of Table I it can be seen that the maximum length of the spathe is recorded during the second flowering stage, the same results are recorded for the width of the spathe. Pollinators can be classified into three groups depending on the length of the spathe. Group with short spathe (P8 and P3) which length of the longest inflorescence is less than $1.12 \mathrm{~m}$, group with medium spathe (ABD1) which length of the inflorescence is between $1.15 \mathrm{~m}$ and $1.30 \mathrm{~m}$. The third group is formed by long spathe (P4, P7, and P13) which length of the longest spathe exceeds $1.50 \mathrm{~m}$. These values are close to the intervals reported by Bchini [15] and which is between 80 and $150 \mathrm{~cm}$, however they are greater than those of Babahani [16] and which are between 60 and $100 \mathrm{~cm}$. According to Naser et al. [14], the length of the spathes is a good indicator of pollen quality; in fact, pollinators with large spathes have pollen grains with a metaxeniceffect inducing the precocity of maturation [15]. The analysis of variance showed a significant variation in the number of spikelets per spathe and per flowering stage. From Table I, we can see that the maximum number of spikelets is reached during the second flowering in all cultivars. The analysis of variance showed a significant variation in the number of spikes per spathe and per flowering stage. From Table 1 we can see that the maximum number of spikelets is reached during the second flowering in all cultivars. The maximum of spikelet is obtained with the pollinator P8 (450), while the minimum is recorded with the pollinator P13 (205). Traditionally, phoeniculturists use 1 to 3 male ears per female bunch [18]. The number of ears varies from 3 to 5 per bunch depending on the variety to be pollinated [1]. In addition, the number of spikelets produced per pollinator varies depending on the cultivar and flowering stage (table 1). The highest number of spikelets is recorded for cultivar P7 (427), while the lowest number is obtained for pollinator P13 (163) the maximum number of spikelets is obtained with the second flowering stage, these results are in agreement with those found by Rekis et al. [19]. The weight of the spadices oscillates between $1481 \mathrm{~g}$ and $3850 \mathrm{~g}$, in fact, $22 \%$ of the spadices have less than $2000 \mathrm{~g}$, and $45 \%$ have a weight between 2100 and $2700 \mathrm{~g}$, while $33 \%$ concerns the spadices which weigh more than $3 \mathrm{~kg}$. These values are slightly higher than the intervals reported by Babahani [20] and Rekis et al. [19]. The results show that the length of the spikelets with flowers reaches the maximum in the second flowering stage, which therefore has a direct effect on the increase in pollen grain production. Concerning the shape of the spathe, $66 \%$ present the lanceolate form, $16 \%$ present the fusiform form and even $16 \%$ the swollen form (Table III), and these results are in agreement with those of Elkadri et al. [9]. From Table III we notice that the majority of qualitative characters are similar between the three flowering conditions only for the spikelet density character which varies from one stage to another for the two pollinators $\mathrm{ABD} 1$ and $\mathrm{P} 7$, these results are in agreement with those found by Rekiset al. [19]. and Simozraget al. [21].

\section{Phylogenetic Relationship}

The similarity coefficients were processed by the INTSYS software's WPGMA analysis program (version 2.02) to obtain a dendrogram that groups the different six male genotypes at each flowering stage/cycle (early, medium, and late) (Fig. 4). In this regard, two groups were distinguished. Group A contains the genotypes 'P4' and 'P7' for the three flowering stages. This group was divided into two subgroups, the first was composed of 'P7' and 'P4' at stage 2 while the second is subdivided into two sub-groups, one contains 'P7' at flowering stage 1 and 3 and the other consists of 'P4' at the early and late flowering stage of flowering. Group B is composed of pollinators 'ABD1', 'P3', 'P8' and 'P13' from the three flowering stages. This group is divided into two subgroups, the first consisting of 'P13' at various flowering stages and 'ABD1' at the late stage. The second subgroups included the remaining genotypes. Morphological studies of date palms have always been considered difficult to perform since they require a large set of phenotypic data and because date palms are quite diverse due to the environmental effect [22]. According to our results, it seems that the studied six male genotypes of date palm is characterized by a high level of genetic similarity of inflorescences at each flowering stage. This is strongly supported by projection of genotypes in the main PCA plane and in the analysis of WPGMA clusters.

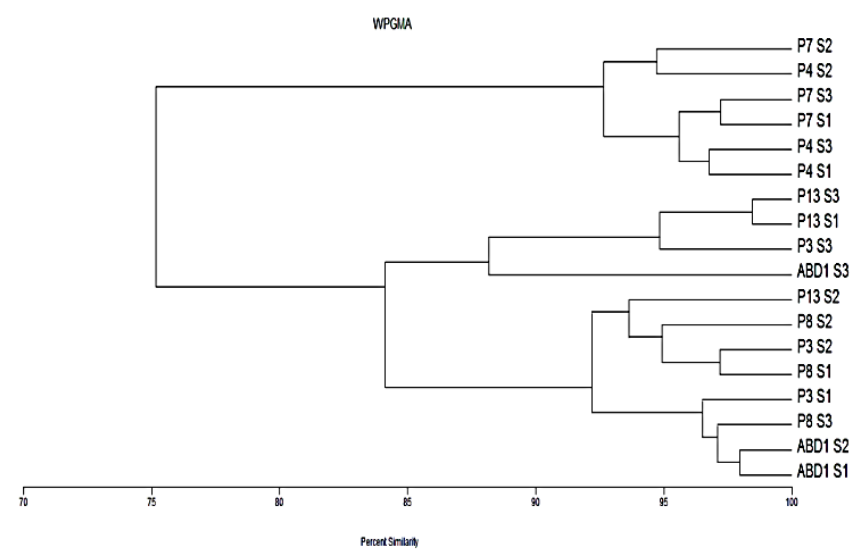

Fi. 4. Dendrogram regroups of the six male date palm genotypes at various flowering stages (S1, S2 and S3, referring to early, medium, and late flowering stage/cycle, respectively) using morphological parameters of the inflorescences according to the WPGMA method of the NTSYS software.

In our study, this discrimination between the studied six male genotypes could be analyzed based essentially on the following criteria: weight of the spathe (SW), number of spathe (NS), shape of spathe (SS), total length of the spathe (TLS), shape of spikelets (SPS), number of spikelets per spathe (NS), length of part of spikelet without fruit at base of spathe (LSWFBS), number of flowers per shortest spikelet (NFSS) and length of part of spikelet with flower at base of the spathe (LSFBS).Morphological parameters have been used in several studies for the analysis of genotypes diversity in date palm. Al-Ghandiet al. [23] reported that the effectiveness of morphological traits associated with the inflorescence in differentiating between the male 'Succary' 
and other male genotypes. Iqbal et al. [24] evaluated and selected 15 elite male genotypes in Pakistan based mainly on the floral organ characteristics (length of the spike, number of flowers, etc.). Likewise, Soliman et al. [25] showed that the inflorescence characteristics were the most distinguishing factor of the male date palm 'Succary' from other genotypes. Kadri et al. [7] analyzed 38 Tunisian date palm male genotypes based mainly on the characters of the spikelets and flowers than the characters of spathes and accordingly classified these males in three categories: good, medium, and bad. All these aspects showed the importance of the phenotypic study of the inflorescences and their great variability among date palm male genotypes. Several other studies have shown that morphological traits can be used to distinguish between date palm cultivars, including male genotypes ([7], [9], [24]-[29]). Our results confirm those of Bchini [15], who reported that the spathes morphological differences among different three flowering stages/cycles (early, medium, and late) during the flowering period were not significant in a Tunisian collection of 16 male date palm genotypes. In the current study, the various multi analyses of the inflorescence morphological parameters allowed to structure preliminary genetic relationships among the various stages of spathe emission of the studied six male date palm genotypes.

\section{CONCLUSION}

From the results obtained, we notice that there is no remarkable difference between the three flowering stages according to the qualitative characteristics of the inflorescences. However, in terms of quantity we notice that the second flowering stage is characterized by the most efficient sizes of the inflorescence (languor, width, weight, size, and number of spikelets...). our results can be very useful for farmers when collecting inflorescences for pollination, in fact these results encourage farmers to use spathe from the second flowering to ensure a good pollination and a good yield of dates.

\section{ACKNOWLEDGMENT}

We express our sincere gratitude to $D r$. Machia Sihem, head of the experimental unit at the regional oasis agriculture research center for his support in the statistical analysis of the data and for his logistical help for the collection of inflorescences.

\section{REFERENCES}

[1] K. Kadri, A. Othmani, S. Makhloufi, M.S. Chebbi, A. Chokmani, and A. Touil, "Contribution to the study of the effect of pollination mode on fruit set rate and yield in the date palm (Phoenix dactylifera L.) in the oases of Tozeur (Tunisia)", Int. J. Agric. Innov. Res, vol. 7, pp. 533537, February 2019.

[2] A. Othmani, M. Jemni, K, Kadri, S. Amel, F. Artes, and J.M. AlKhayri, "Preharvest fruit drop of date palm (Phoenix dactylifera $L$.) CV. Deglet Nour at Kimri Stage: development, physico-chemical characterization, and functional properties", Int. J. Fruit Sci, pp. 1-19. 2019. doi: 10.1080/15538362.2019.1651241.

[3] M. Belguedj, "Les ressources génétiques du palmier dattier : caractéristiques des cultivars de dattier dans les palmeraies du Sud-Est Algérien", Revue annuelle de l'INRAA, vol. 1, pp. 280-289, 2002.
[4] F. Aberlenc-Bertossi, A. Daher, and N. Chabrilllange, "La détermination du sexe chez le palmier dattier. Biotechnologies végétale set gestion durable des résistances face à des stress biotiques et abiotiques", XIe Journées Scientifiques. Rennes. France, pp. 227-236, 2008.

[5] A. Rhouma, "Le palmier dattieren Tunisie. Le patrimoine génétique", Vol. 1, Arabesques Editions et Créations, Tunis, Tunisie, 1994.

[6] K. Karim, H. Barrani, K. Chatti, N. Kadri, and F. Ben Hmida, "Genetic diversity analysis of a local Date palm pollinators collection (Phoenix dactylifera L.) using SSR Markers and study of their metaxenic effects on the maturation and quality of Dates obtained", Academia Journal of Agricultural Research, vol. 3(12), pp. 381-394, December 2015.

[7] K. Kadri, I. Raddaoui, S. Makhlouf, K. Hcini, "Morphological and molecular evaluation of the genetic diversity of Tunisian local date palm pollinators", Academ. J. Biotechnol, vol.3, pp. 26-34. August, 2015 .

[8] K. Kadri, W. Baba, Z. Golem, S. Makhlouf and H. Barrani, “Analysis of morpho-physiological diversity of some Tunisian date palm pollinators and study of their whorl pollen grain on fruit set, the time of ripening and yield of Date palm cv. Deglet Nour", International Journal of Current Agriculture Science, (IJCAS), vol. 6, issue5, pp. 3443, May 2016.

[9] N. El Kadri, M. Ben Mimoun, and J.I. Hormaza, "Genetic diversity of Tunisian male date palm (Phoenix dactylifera L.) genotypes using morphological descriptors and molecular markers", Sci. Hortic, vol. 25, pp. 24-34. 2019. doi: 10.1016/j.scienta.2019.04.026.

[10] M. Djerbi, "Précis de Phoeniciculture", FAO, Rome. pp. 192. 1994.

[11] Ipgri, Inraa, Inram, Inrat, Fem, Pnud, "Descripteurs du palmier dattier (Phoenix dactylifera L.)", Rome : International Plant Genetic Resources Institute (IPGRI); Fonds pour l'Environment Mondial (FEM); Programme des Nations Uniespour le De'veloppement (PNUD); Institut National de la Recherche Agronomique, d'Algérie, $\mathrm{du}$ Maroc et de Tunisie (INRAM) (INRAT), pp.30-37, 2005.(bioversityinternational.org).

[12] M. Nei, and W. Li, "Mathematical model for studying genetic variation in terms of restriction endonucleases", Proc. Natl. Acad. Sci, USA. 76, pp. 5269-5273. 1979.

[13] H. Bchini, S. Hsayoui, and S. Aloui, "Gestion de la matière organique et compostage des palmes sèches dans le milieu oasien”, Les annales de l'INRAT, vol. 75, pp. 299-312, 2002.

[14] T.A. Nasr, M.A. Shaheen, and M.A. Bacha, "Evaluation of seeding male palms used in pollination in the central region of Saudi Arabia", Date Palm journal, vol. 8, pp. 163-175,1986.

[15] H. Bchini, "Quelques critères morphologiques de sélection indirecte des pollinisateurs à effets métaxéniques chez la variété de palmier dattier" Deglet Nour" de Tunisie", Plant Genetic ressources newsletter, vol. 145, pp. 46-60, 2006.

[16] S. Babahani, "Analyses biologique et agronomique de palmiers males (Dokkars) et conduite de l'éclaircissage des fruits chez les cultivars Deglet Nour et Ghars. Thèse de Doctorat", Ecole Nationale Supérieure d'Agronomie El Harrach, Alger, pp. 86-139. 2011.

[17] A. Zaid, and P.F. de Wet, "Pollination and Bunch Management", In: Zaid, A., Ed., Date Palm Cultivatio, Chapter 8, FAO, Plant Production and Protection, 156. 2002.

[18] G. Toutain, "Le palmier dattier. Culture et production", In : Al Awamia, vol 25, pp.83-151, 1967.

[19] A. Rekis, Z. Laiadi, and M. Mehenni, "Morphological characteristics denomination of date palm studied cultivars", Algerian Journal of Arid Regions, (JARA), vol 14 (1). Scientific and Technical Research Centre for Arid Areas (CRSTRA), Algeria, pp. 131-140, 2020.

[20] S. Babahani, and N. Bouguedoura, "Effet de quelque méthode simple de conservation du pollen sur les caractères de la production dattière", Revue Sciences et technologie, vol. 30, pp. 9-15, 2009.

[21] A. Simozrag, A. Chala, A. Djerouni, and M. Elmoncef Bentchikou, "Phenotypic diversity of date palm cultivars (Phoenix dactylifera L.) from Algeria", J. Gayana Botánica, vol. 73, pp. 42-53, 2016.

[22] P. Munier, "Le pays de Dilmounet la culture du palmier-dattier", Fruits, vol. 28(9), pp. 641-642,1973.

[23] A.S. Al-Ghandi, A. Al-Bahrany, and J. Al-Khayri, "Evaluation of date palm males used in pollination in Al-Hassa area", Final report research project N.1024-238, King Faisal Univ. Deanship of Scientific Research, pp. 1-30, 2002.

[24] M. Iqbal, J. Ud-Din, M. Munir and M. Khan, "Floral characteristics of the different mal date palms and their response to fruit setting and yield of CV Dhakki”, Pakistan, J. Agric. Res., Vol 22, pp. 36-41, 2009.

[25] S.S. Soliman, R.S. Al-Obeed, A.A. Omar, and M.A. Ahmed, "A Comparative study of the morphological characteristics of some seedling Date Palm Males", J. App. Sci. Res., vol 9(7), pp. 4463- 4468. 2013. 
[26] N. Faqir, "Simple sequence repeat (SSR) markers show greater similarity among morphologically diverse date palm (Phoenix dactylifera L.) cultivars grown in Pakistan”, Pure Appl. Biol, vol. 5 (3), pp. 483-498. 2016. https://doi.org/10.19045/bspab.2016.50063.

[27] A. Djerouni, A. Chala, A. Simozrag, R. Benmhaia, and M. Baka, "Evaluation of male palms used in pollination and the extent of its relationship with cultivars of datepalms (Phoenix dactylifera $\mathrm{L}$.) grown in region of OuedRigh, Algeria", Pakistan Journal of Botany, vol. 47, pp. 2295-2300, 2015.

[28] M. Elsafy, L. Garkava-Gustavsson, and C. Mujaju, "Phenotypic diversity of date palm cultivars (Phoenix dactylifera L.) from Sudan estimated by vegetative and fruit characteristics", Int. J. Biodivers 610391. https://doi.org/10.1155/2015/610391.2015

[29] A.O.M. Salem, S. Rhouma, S. Zehdi, M. Marrakkchi, and M. Trif, "Morphological variability of Mauritanian date-palm (Phoenix dactylifera L.) cultivars as revealed by vegetative traits", Acta Bot. Croat, vol. 6, 81-90, 2008.

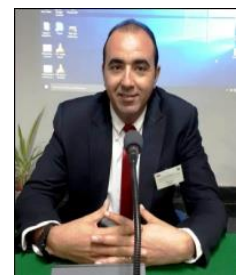

Kadri Karim was born in Tunisia in $1978 . \mathrm{He}$ received the Diploma of engineering in Biotechnology from the National Institute of Applied Science and Technology (INSAT) in 2003 and the master's degree on Genetic and molecular biology in 2005 and the $\mathrm{PhD}$. degree in Biology in 2016 from the faculty of sciences of Tunisia. He joined the National Institute of agronomic research of Tunisia, in 2004 as an engineer; His task was morpho-physiological evaluation of barley accessions under salt stress. Since 2007, he has been affected in the Regional Research Center of Oasis Agriculture, as the university assistant, where he is currently the head of laboratory of biotechnology and genetic resources. His main areas of research interest are conservation and improvement of Date Palm genetic resources. His research activities are focused on the morphological, physiological, and molecular characterization of date palm cultivars in view of their preservation and conservation. Dr Kadri was interested by another filed of research, improving production efficiency in the date palm by the selection of metaxenic pollinators. Dr Kadri is the author and co-authored of many publications with Impact Factor, and over then 15 international articles as book chapters and proceedings of international congresses. He contributed to the organization of over 10 International congresses and courses in Tunisia and abroad and he reviewed papers for many International Journals. Dr. Kadri supervised many undergraduate and graduate students and developed collaborative projects bilateral research conventions. Dr. Kadri is a member of many scientific communities and structures, Laboratory of Biotechnology applied to agricultural (INRAT), the Tunisian Association of Genetic Resources (TAGR), the Tunisian Association of Biotechnology (ATB) and the Tunisia Dattes \& Palm Cluster. 